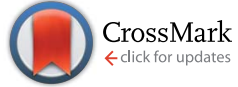

Cite this: J. Mater. Chem. A, 2017, 5, 5195

Received 28th December 2016 Accepted 7th February 2017

DOI: $10.1039 / c 6 t a 11139 d$

rsc.li/materials-a

\section{Enhanced perovskite electronic properties via a modified lead(II) chloride Lewis acid-base adduct and their effect in high-efficiency perovskite solar cells $\dagger$}

\author{
Ngoc Duy Pham, ${ }^{a}$ Vincent Tiing Tiong, ${ }^{a}$ Peng Chen, ${ }^{b}$ Lianzhou Wang, \\ Gregory J. Wilson, ${ }^{c}$ John Bell ${ }^{\mathrm{a}}$ and Hongxia Wang*a
}

Methylammonium lead triiodide $\left(\mathrm{MAPbl}_{3}\right)$ perovskite solar cells have gained significant attention with an impressive certified power conversion efficiency of $22.1 \%$. Suppression of recombination at the interface and grain boundaries is critical to achieve high performance perovskite solar cells (PSCs). Here, we report a simple method to improve the performance of PSCs by incorporating a lead chloride $\left(\mathrm{PbCl}_{2}\right)$ material into the $\mathrm{MAPb}_{3}$ perovskite precursor through a Lewis acid-base adduct. The optimal concentration of $\mathrm{PbCl}_{2}$ that helps increase the grain size of $\mathrm{MAPbl}_{3}$ with introduction of the ideal amount secondary phases (lead iodide and methylammonium lead tri-chloride) is $2.5 \%$ (molar ratio, relative to lead iodide). Examination by steady-state photoluminescence and time-resolved photoluminescence has shown that devices based on $\mathrm{MAPbl}_{3}-2.5 \%$ of $\mathrm{PbCl}_{2}$ facilitated longer charge carrier lifetime and electron-hole collection efficiency which is ascribed to reduced defects and concurrent improved material crystallinity. Electrochemical impedance spectra (EIS) of the corresponding PSCs have revealed that, compared to the pristine $\mathrm{MAPbl}_{3}$ perovskite film, the $2.5 \% \mathrm{PbCl}_{2}$-additive increased the recombination resistance of the PSCs by 2.4 -fold. Meanwhile, measurement of the surface potential of the perovskite films has indicated that the $\mathrm{PbCl}_{2}$ additive modifies the electronic properties of the film, shifting the fermi-level of the MAPbl 3 film by 90 meV, leading to a more favourable energetic band matching for charge transfer. As a result, the performance of PSCs is enhanced from an average efficiency of $16.5 \%$ to an average efficiency of $18.1 \%$ with maximum efficiency reaching $19 \%$ due to the significantly improved fill-factor (from 0.69 to 0.76 ), while the hysteresis effect is also suppressed with the $\mathrm{PbCl}_{2}$-additive.

\section{Introduction}

Perovskites based on organic-inorganic lead halides with a formula of $\mathrm{APbX}_{3}(\mathrm{~A}=$ methylammonium (MA), formamidinium (FA); $\mathrm{X}=\mathrm{I}, \mathrm{Br}$, and $\mathrm{Cl}$ ) have attracted significant research interest due to their excellent optoelectronic properties and low-cost fabrication process. ${ }^{1}$ Perovskite solar cells (PSCs) which originally adopted the structure of a traditional dyesensitized solar cell using an iodide/triiodide based liquid electrolyte and $\mathrm{MAPbI}_{3}$ nanoparticles as a light absorber were reported by Kojima et al. in 2009. ${ }^{1}$ Following this seminal report, a significant increase in device performance has been

${ }^{a}$ School of Chemistry, Physics and Mechanical Engineering, Science and Engineering Faculty, Queensland University of Technology, Brisbane, Australia. E-mail: hx. wang@qut.edu.au

${ }^{b}$ School of Chemical Engineering, Australian Institute for Bioengineering and Nanotechnology, The University of Queensland, St Lucia, Brisbane, 4072, Australia ${ }^{c}$ CSIRO Energy, Mayfield West, NSW 2304, Australia

$\dagger$ Electronic supplementary information (ESI) available. See DOI: 10.1039/c6ta11139d achieved through use of solid state hole transport materials for example, 2,2' $7,7^{\prime}$-tetrakis-( $N, N$-di-4-methoxyphenylamino)-9,9'spirobifluorene more commonly referred to in the literature as Spiro-OMeTAD. The power conversion efficiency (PCE) of solidstate PSCs has soared from $9.7 \%$ in 2012 to a validated PCE of $22.1 \%$ in early $2016 . .^{3,4}$ Recent reports have suggested that the presence of a small amount of secondary phases such as lead iodide $\left(\mathrm{PbI}_{2}\right)$ and/or methylammonium lead tri-chloride $\left(\mathrm{MAPbCl}_{3}\right)$ in final perovskite films leads to improved performance of devices. ${ }^{2-4}$ Furthermore, these studies have shown that un-reacted $\mathrm{PbI}_{2}$ is mainly located at the grain boundaries (GBs) of the $\mathrm{MAPbI}_{3}$ film potentially passivating GBs and reducing recombination in the perovskite film, ${ }^{2}$ while $\mathrm{MAPbCl}_{3}$ acts as a template for the crystallization of $\mathrm{MAPbI}_{3}$ perovskite. ${ }^{5}$

The solar cell devices that use chloride-based (Cl-based) perovskite layers have demonstrated superior PCE compared to solar cells made with $\mathrm{Cl}$-free, $\mathrm{MAPbI}_{3}$ counter-parts. ${ }^{6-9}$ Stranks et al. pointed out that the electron and hole diffusion length of perovskite films made from the Cl-based precursor can be enhanced from about $100 \mathrm{~nm}$ to over $1 \mu \mathrm{m},{ }^{\mathbf{1 0}}$ indicating 
a reduced recombination in the bulk perovskite layer or at interfaces between the perovskite layer and selective contacts. Lead chloride $\left(\mathrm{PbCl}_{2}\right)$ has been used as a Cl-source for preparing Cl-based perovskite films. ${ }^{11,12}$ The use of lead chloride $\left(\mathrm{PbCl}_{2}\right)$ as an alternative to $\mathrm{PbI}_{2}$ in the perovskite precursor was reported to improve the uniformity and surface coverage of $\mathrm{MAPbI}_{3}$, controlling its nucleation. ${ }^{9}$ Higher concentrations of $\mathrm{PbCl}_{2}$ in the perovskite precursor induced increased numbers of perovskite crystallites, thus leading to improved film morphology. Furthermore, Huang et al. added additional $\mathrm{PbCl}_{2}$ (3 at\% extra) to form a non-stoichiometric perovskite precursor with $\mathrm{PbCl}_{2}$ $:$ MAI $=1.03: 3$ (molar ratio) and found that the excess $\mathrm{PbCl}_{2}$ facilitated the solubility of MAI in the perovskite precursor. ${ }^{13} \mathrm{~A}$ PCE up to $16.1 \%$ was achieved with an average PCE of $13.82 \%$ based on $\mathrm{PbCl}_{2}$-assisted heterogeneous nucleation crystallization. Nevertheless, the effect of excess $\mathrm{PbCl}_{2}$ on the nucleation process of $\mathrm{MAPbI}_{3}$ is still unclear. For instance, if $\mathrm{PbCl}_{2}$ acts as a heterogeneous nucleation site, then the small increment in the content of $\mathrm{PbCl}_{2}$ in the original precursor solution (from 1 to 1.03 molar ratio with respect to $3 \mathrm{MAI}$ ) actually did not significantly increase the number of seeds (no more than $3 \%$ with respect to the original number of seeds) for crystal growth.

Although the benefits of $\mathrm{Cl}$ on electronic and morphological properties of $\mathrm{MAPbI}_{3}$ films are excellent, the exact location and the amount of $\mathrm{Cl}$ as well as the formation of Cl-based products in the final perovskite films remain unclear. Colella et al. have suggested that $\mathrm{Cl}$ is preferentially located near the perovskite/ $\mathrm{TiO}_{2}$ interface, which in turns induces band banding and improves charge collection efficiency of $\mathrm{TiO}_{2}{ }^{6}$ Song et al. proposed that the perovskite film prepared from a mixture of $\mathrm{PbCl}_{2}$ and MAI consists of $\mathrm{MAPbI}_{3}$ and secondary phases, e.g., $\mathrm{PbI}_{2}$ and $\mathrm{MAPbCl}_{3} \cdot{ }^{4}$ The amount of these secondary phases strongly influences the PCE of PSCs. For instance, above the "optimal amount" of secondary phases, solar cells showed lower photovoltage while below that optimized value solar cells show lower photocurrent and thus lower PCE. ${ }^{4}$ In mixed halide perovskite films prepared from stoichiometric $\mathrm{MAI}: \mathrm{PbCl}_{2}$ ( $3: 1$, molar ratio), the amount of the secondary phases is often controlled by tuning annealing temperature and time $\left(100{ }^{\circ} \mathrm{C}\right.$, 90 minutes) which is somehow unreliable due to the intrinsic thermal instability of $\mathrm{MAPbI}_{3}$ perovskite. ${ }^{\mathbf{1 4}}$

It has been established that due to the dewetting or agglomeration process of the as-deposited perovskite films prepared from a simple one-step spin-coating method, upon annealing, pin-holes and voids are often observed in the perovskite film even with inclusion of $\mathrm{PbCl}_{2}$ in the precursor and careful solution preparation. ${ }^{12}$ Several methods have been developed to control the crystallization processes of perovskites

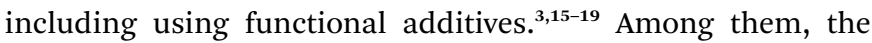
method based on antisolvent-dripping which takes place by sudden inducement of super-saturation in the film is found to be very effective, ${ }^{3,15,16}$ resulting in the formation of a smooth perovskite film with full surface coverage. Recently, Ahn et al. reported a modified antisolvent-dripping method which can effectively retard the crystal growth process of the perovskite material by forming a Lewis acid-base (MAI-PbI ${ }_{2}$-dimethyl sulfoxide (DMSO)) adduct and make the $\mathrm{MAPbI}_{3}$ film with high quality and full surface coverage. ${ }^{16}$ To date, as reported, this is an effective approach to produce high performance $\mathrm{MAPbI}_{3}$ solar cells. However, current-voltage hysteresis is still observed in the reported $\mathrm{MAPbI}_{3}$ perovskite solar cell probably due to an inherent unbalanced electron-hole diffusion length $(\sim 130 \mathrm{~nm}$ for electrons, $\sim 90 \mathrm{~nm}$ for holes). ${ }^{20}$ Here we introduce a $\mathrm{PbCl}_{2}$ additive in the Lewis acid-base adduct method to fabricate a hysteresis-less high PCE solar cell, which has not been previously reported. Since the impact of $\mathrm{PbCl}_{2}$ on improving the morphology of the perovskite film using the Lewis acid-base adduct method is marginal, this allows us to uncover the underlying reasons for the change of device performance by focusing on the modification of electronic properties of the perovskite material. We have found that this simple method successfully establishes effective secondary phases $\left(\mathrm{PbI}_{2}\right.$ and $\mathrm{MAPbCl}_{3}$ ) in the perovskite material while minimizing the adverse effect of annealing. These secondary phases and the incorporation of chloride into the perovskite lattice enable high PCE solar cells with less hysteresis and an improved fill factor.

\section{Experimental}

\section{Materials preparation}

All materials were purchased from Sigma-Aldrich and used as received without further purification unless otherwise stated. $\mathrm{MAPbI}_{3}$ perovskite precursor solution was prepared in an argonfilled glovebox by dissolving $461 \mathrm{mg}$ of $\mathrm{PbI}_{2}, 159 \mathrm{mg}$ of methylammonium iodide (MAI) (Dyesol), and $78 \mathrm{mg}$ of dimethyl sulfoxide (DMSO) in $700 \mathrm{mg}$ of dimethyl formamide (DMF) at room temperature, under rigorous stirring for one hour. Mixed halide perovskite $\mathrm{MAPbI}_{3}-\mathrm{PbCl}_{2}$ additive precursor solution was prepared by adding different amounts of $\mathrm{PbCl}_{2}(1 \%, 2.5 \%$, $5 \%, 7.5 \%$, and $10 \%$ (molar ratio with respect to $\mathrm{PbI}_{2}$ )) to the prepared $\mathrm{MAPbI}_{3}$ perovskite precursor. The solution was then magnetically stirred for an additional hour. The prepared perovskite solution was filtered by using a syringe filter (pore size: $0.22 \mu \mathrm{m}$ ) prior to use for deposition of the film. A solution for the hole transporting material was prepared by addition of $72.3 \mathrm{mg}$ of $2,2^{\prime}, 7,7^{\prime}$-tetrakis-( $N, N$-di-4-methoxyphenylamino)9,9'-spirobifluorene (Spiro-MeOTAD) (Borun New Material), $28.8 \mu \mathrm{L}$ of 4 -tert-butylpyridine, and $17.5 \mu \mathrm{L}$ of bis(trifluoromethane)sulfonimide lithium (Li-TFSI) solution $(520 \mathrm{mg}$ of $\mathrm{Li}$ TFSI in acetonitrile) into $1 \mathrm{~mL}$ of chlorobenzene.

\section{Device fabrication}

Solar cells were fabricated using fluorine-doped tin oxide (FTO) coated glass (Nippon Electric Glass, $15 \Omega \square^{-1}$ ) as the substrate which was firstly patterned through partial removal of FTO via etching using $35.5 \mathrm{wt} \% \mathrm{HCl}$ and zinc powder. The substrates were then cleaned in sequence in 5\% Decon-90 detergent, and a mixture of acetone, isopropanol and ethanol for $20 \mathrm{~min}$ each in an ultrasonic bath. Prior to use, the substrates were treated with ultraviolet ozone for $30 \mathrm{~min}$ to fully remove organic solvent residuals. An electron transporting layer based on the $\mathrm{TiO}_{2}$ film $(\sim 40 \mathrm{~nm})$ was deposited in air via spin-coating a $0.15 \mathrm{M}$ solution of titanium diisopropoxide bis(acetylacetonate) in 1-butanol at 
$2000 \mathrm{rpm}$ for $20 \mathrm{~s}$. The film was then dried at $125{ }^{\circ} \mathrm{C}$ for $5 \mathrm{~min}$ and annealed at $450{ }^{\circ} \mathrm{C}$ for $30 \mathrm{~min}$. A mesoporous $\mathrm{TiO}_{2}(\mathrm{mp}-$ $\left.\mathrm{TiO}_{2}\right)$ layer $(\sim 200 \mathrm{~nm})$ was spin-coated onto the compact $\mathrm{TiO}_{2}$ film using a diluted $\mathrm{TiO}_{2}$ paste $\left(0.12 \mathrm{~g} \mathrm{TiO}_{2}\right.$ paste (Dyesol) in 1 $\mathrm{mL}$ of absolute ethanol) at $2000 \mathrm{rpm}$ for $20 \mathrm{~s}$, followed by sintering at $450{ }^{\circ} \mathrm{C}$ for $30 \mathrm{~min}$. After cooling to room temperature, the film was treated with $20 \mathrm{mM} \mathrm{TiCl}_{4}$ aqueous solution at $90{ }^{\circ} \mathrm{C}$ for $10 \mathrm{~min}$. The $\mathrm{TiCl}_{4}$-treated film was cleaned with distilled water and annealed again at $450{ }^{\circ} \mathrm{C}$ for $30 \mathrm{~min}$. After this, the $\mathrm{TiO}_{2}$ coated film was treated in a UV-zone for $20 \mathrm{~min}$ before being transferred to an Ar-filled glovebox. Perovskite layers $(\sim 400 \mathrm{~nm})$ with and without $\mathrm{PbCl}_{2}$ in the perovskite precursor solution were deposited onto the prepared $\mathrm{TiO}_{2}$ layer at $4000 \mathrm{rpm}$ for $20 \mathrm{~s}$. During spin-coating, $0.5 \mathrm{~mL}$ of diethyl ether was dropped on the center of the spinning substrate before it turned turbid. The perovskite layer was then dried at $65{ }^{\circ} \mathrm{C}$ for $1 \mathrm{~min}$, and annealed at $100{ }^{\circ} \mathrm{C}$ for $2 \mathrm{~min} .{ }^{\mathbf{1 6}}$ The hole-transport layer $(\sim 200 \mathrm{~nm})$ was deposited from the prepared SpiroOMeTAD solution onto the as-prepared perovskite layer at $4000 \mathrm{rpm}$ for $25 \mathrm{~s}$. The device fabrication was finished by deposition of a $100 \mathrm{~nm}$ layer of gold film for back contact on the prepared sample via an e-beam evaporation process under $10^{-6}$ torr pressure.

\section{Characterization}

The top-view and cross-sectional scanning electron microscopy (SEM) images of the samples were taken using a field emission scanning electron microscope (FSEM JOEL 7001F) at an acceleration voltage of $5 \mathrm{kV}$. The UV-vis absorbance spectrum was measured with a UV-visible spectrometer (Cary 50). The crystal structure of the perovskite film as-deposited on FTO/compact $\mathrm{TiO}_{2} / \mathrm{mp}-\mathrm{TiO}_{2}$ was determined by X-ray diffraction (Rigaku SmartLab) with monochromatic $\operatorname{CuK} \alpha(\lambda=0.154 \mathrm{~nm})$ as an excitation source. A scan rate of $1.5^{\circ}$ per minute and a step size of $0.015^{\circ}$ were used in the XRD measurement. The performance of perovskite devices was measured under irradiation of 100 $\mathrm{mW} \mathrm{cm}^{-2}$ (AM1.5) provided by a solar simulator (Oriel Sol3A, Newport) equipped with a $450 \mathrm{~W}$ Xenon lamp. IPCE measurement was conducted by using a quantum efficiency system (IQE 200B, Newport) in AC mode. Electrochemical impedance spectroscopy (EIS) of the PSCs was performed in a frequency range from $1 \mathrm{MHz}$ to $100 \mathrm{mHz}$ using an electrochemical workstation (VSP BioLogic Science Instruments) at a forward bias of $0.5 \mathrm{~V}$ in darkness. An AC voltage with a perturbation amplitude of $10 \mathrm{mV}$ was applied in the EIS measurement. X-ray photoelectron spectroscopy (XPS) (Kratos Axis Ultra) using mono Al Ka (1486.6 eV) X-rays was used to detect the elements in the perovskite film. For XPS depth profiling, a $4 \mathrm{keV} \mathrm{Ar}^{+}$ion was used for the charge-up effect. The photoluminescence (PL) spectrum was measured with a fluorescence spectrometer (Edinburgh Instruments Ltd) at room temperature. The film was photoexcited by using a laser $(474 \mathrm{~nm})$ with a pulse wavelength of 82.4 ps. Scanning Kelvin Probe Force Microscopy (KPFM) (Oxford instrument, Asylum Research) was performed on the prepared perovskite film under ambient conditions using a NSG-03 Pt coated cantilever at room temperature. The work function of the cantilever was measured using a HOPG standard sample. The chloride analysis was performed on a Dionex RFIC ICS-2100 Ion Chromatography (IC) system (Thermo Scientific) with an ASDV auto sampler system. A Dionex-IonPac AS18 $4 \mathrm{~mm}$ and a Dionex EGC-KOH II Cartridge were used as the column and eluent, respectively. The suppressor (ASRS 300, $4 \mathrm{~mm}$ ) operated at $82 \mathrm{~mA}$. The calibration standards were diluted from an IC standard (containing $1000 \mu \mathrm{g} \mathrm{mL}^{-1}$ of $\mathrm{Cl}$ ) purchased from Choice Analytical. Perovskite/FTO samples $(2 \times 1.5 \mathrm{~cm})$ were immersed into $2 \mathrm{~mL}$ of Milli-Q water in a clean beaker until the perovskite layer was fully removed. The amount of dissolved perovskite material in water was used for further calculation. $1.2 \mathrm{~mL}$ of the resulting solution was pipetted out and further diluted five fold for IC measurements.

\section{Results and discussion}

Depicted in Fig. 1(a)-(e) are the top-view SEM images of perovskite layers with various concentrations of $\mathrm{PbCl}_{2}$ in the precursor solution (from $0 \%$ to $10 \%$ with respect to the content of $\mathrm{PbI}_{2}$ ). The $\mathrm{MAPbI}_{3}$ film consists of grains with the size of 100$300 \mathrm{~nm}$ which are connected closely, resulting in a pinhole-free and highly compact film (Fig. 1a), which is desirable for PSCs. When only $1 \% \mathrm{PbCl}_{2}$ was added into the perovskite precursor, there is no observable change in the film morphology in terms of grain size and film compactness (Fig. 1b) compared to the pure $\mathrm{MAPbI}_{3}$ film. This indicates that a negligible amount of $\mathrm{PbCl}_{2}$ in the perovskite precursor does not dramatically change the surface morphology of the perovskite film in our
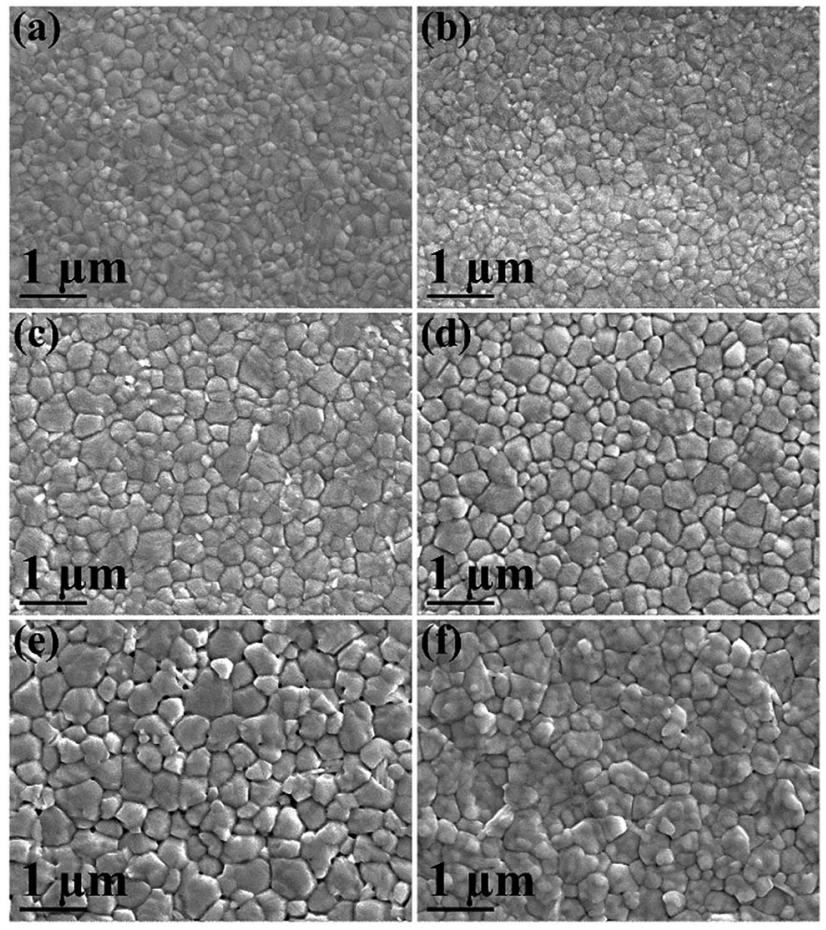

Fig. 1 Top-view SEM images of perovskite films. (a) $\mathrm{MAPb}_{3}$, (b) $\mathrm{MAPbl}_{3}$ $+1 \% \mathrm{PbCl}_{2}$, (c) $\mathrm{MAPbl}_{3}+2.5 \% \mathrm{PbCl}_{2}$, (d) $\mathrm{MAPbl}_{3}+5 \% \mathrm{PbCl}_{2}$, (e) $\mathrm{MAPbl}_{3}$ $+7.5 \% \mathrm{PbCl}_{2}$, and (f) $\mathrm{MAPbl}_{3}+10 \% \mathrm{PbCl}_{2}$. 
experiments. This phenomenon is different from what has been reported previously where a small amount of $\mathrm{PbCl}_{2}(\sim 1 \%)$ significantly improved surface coverage of the perovskite film. ${ }^{13}$ It is ascribed to the effectiveness of the Lewis acid-base adduct method which results in high quality $\mathrm{MAPbI}_{3}$ perovskite films. ${ }^{16,21}$ However, when the $\mathrm{PbCl}_{2}$-additive increased to $2.5 \%$, larger grains with the crystallite size in the range of $300-500 \mathrm{~nm}$ are observed in the perovskite film (Fig. 1c). This effect could be attributed to a better crystallization of the perovskite layer, which leads to larger perovskite crystals in the presence of $\mathrm{PbCl}_{2}$. Probably $\mathrm{MAPbCl}_{3}$ is formed first and then acts as a template to aid grain growth. ${ }^{5}$ To gain more insight into the influence of $\mathrm{PbCl}_{2}$ on the morphological properties of the perovskite film, the concentration of $\mathrm{PbCl}_{2}$ in the $\mathrm{MAPbI}_{3}$ precursor was further increased to $5 \%, 7.5 \%$, and $10 \%$, respectively. As shown in Fig. 1(d)-(f) under the same deposition and annealing conditions, there is no further increase in grain sizes of the perovskite material. Nevertheless, small voids/ pinholes can be seen clearly at the GBs on the surface of perovskite films with precursor solutions in excess of $5 \% \mathrm{PbCl}_{2}$. The number of voids/pinholes increases with the increase of $\mathrm{PbCl}_{2}$ concentration. It is known that voids at the GBs can increase recombination in the device due to poor contact/ necking between the light absorbing particles, thus impacting device performance. Formation of voids in films with over $5 \%$ $\mathrm{PbCl}_{2}$ in the perovskite precursor might be a consequence of the different nucleation rates and competitive growth of nuclei $\mathrm{MAPbI}_{3}, \mathrm{MAPbCl}_{3}$ and $\mathrm{PbI}_{2}$, which somehow affects the surface coverage of the film. ${ }^{9}$ Furthermore, irregular grain sizes are also observed in the perovskite film with $10 \% \mathrm{PbCl}_{2}$ in the precursor solution (Fig. 1f), which could be due to the coexistence of $\mathrm{MAPbI}_{3}$ and methylammonium lead chloride $\left(\mathrm{MAPbCl}_{3}\right)$ as confirmed by XRD (see below). The above SEM results indicate that $2.5 \% \mathrm{PbCl}_{2}$ provides the optimal quality of surface morphology of the perovskite film.

Since the optimal light absorption and energy bandgap are very critical for the performance of a solar cell, the light absorption properties of the $\mathrm{MAPbI}_{3}$ film made from different contents of $\mathrm{PbCl}_{2}$ in the precursor were investigated by ultraviolet-visible (UV-vis) spectroscopy (Fig. S1†). However, negligible change is found in the onset light absorbing wavelength and the intensity of light absorption of the perovskite layers with the content of $\mathrm{PbCl}_{2}$ below $5 \%$. A slight blue-shift in the UV-vis spectrum is observed with the film made from a higher content of the $\mathrm{PbCl}_{2}$ additive (above $5 \%$ ), which could be related to incorporation of chloride into the $\mathrm{MAPbI}_{3}$ crystal lattice, which reduces the lattice symmetry and thus increases the material bandgap ${ }^{22}$ and the coexistence of a small amount of $\mathrm{MAPbCl}_{3}$. The reduction in intensity of light absorption of the film with a higher content of $\mathrm{PbCl}_{2}$ is associated with the existence of more voids as observed in Fig. 1(d)-(f) and possible secondary impurities such as $\mathrm{PbI}_{2}$ and $\mathrm{MAPbCl}_{3}$ in the film as indicated in the XRD (below).

To gain insight into the effects of the $\mathrm{PbCl}_{2}$-additive on the crystal structure of the perovskite material, X-ray diffraction (XRD) data were collected for the diffraction patterns of the films (Fig. 2). From the data, it is found that when the
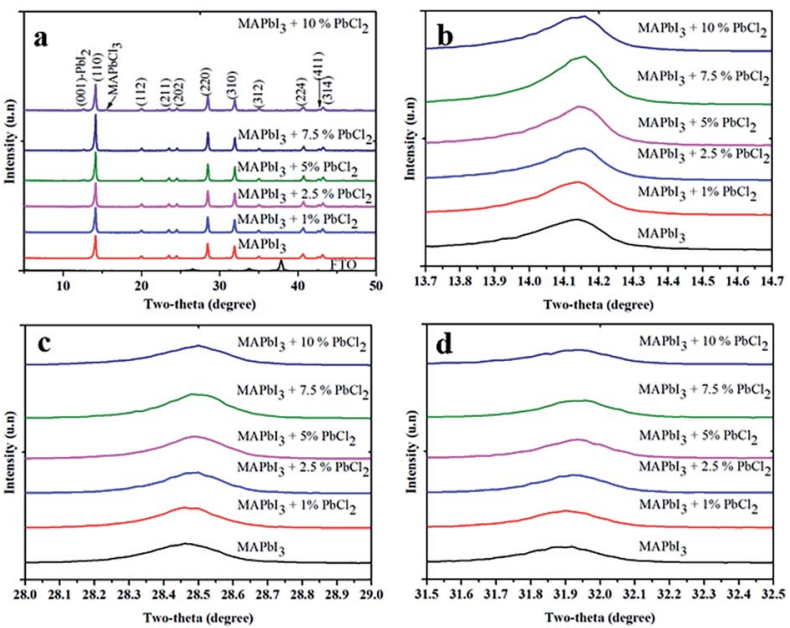

Fig. 2 (a) XRD patterns of $\mathrm{MAPb}_{3}$ films prepared from perovskite precursor solution with different concentrations of $\mathrm{PbCl}_{2}$. Zoom-in XRD patterns showing at (b) (110) lattice plane; (c) (220) plane; and (d) (310) plane.

concentration of $\mathrm{PbCl}_{2}$ is less than $5 \%$, all XRD peaks can be well indexed to the reflection of $\mathrm{MAPbI}_{3}$ without any impurities detected within the instrumental limit of the XRD facility. However, a small peak at $12.8^{\circ}$ which is ascribed to the (001) plane of $\mathrm{PbI}_{2}$ is observed when the amount of $\mathrm{PbCl}_{2}$-additive exceeds $5 \%$. For the film with $10 \% \mathrm{PbCl}_{2}$, a diffraction peak at $15.6^{\circ}$ which belongs to the reflection of the (110) plane of methylammonium lead tri-chloride $\left(\mathrm{MAPbCl}_{3}\right)$ is also observed. It is worth noting that no peak from $\mathrm{PbCl}_{2}$ is observed in all the $\mathrm{XRD}$ spectra, indicating that the added $\mathrm{PbCl}_{2}$ is completely consumed in the reaction with MAI to either form $\mathrm{PbI}_{2}$ or $\mathrm{MAPbCl}_{3}$. This is in good agreement with a previous study. ${ }^{\mathbf{1 6}} \mathrm{A}$ moderate excess of $\mathrm{PbI}_{2}$ in the $\mathrm{MAPbI}_{3}$ perovskite film which mainly exists at GBs is beneficial because it forms an energy barrier that hinders leakage of both electrons and holes from $\mathrm{MAPbI}_{3}$ for recombination. ${ }^{23}$ However, a large amount of $\mathrm{PbI}_{2}$ in the perovskite film is detrimental for light harvesting due to its much larger bandgap (2.41 eV for $\mathrm{PbI}_{2}$ ) and low light absorption, which in turns reduces the current density of devices. ${ }^{2}$ Furthermore, a small shift of the XRD patterns towards the smaller angle of $\mathrm{MAPbI}_{3}$ was observed with the presence of $\mathrm{PbCl}_{2}$ in the precursor (Fig. 2(b)-(d)). For example, by comparison of the XRD patterns, it is found that peaks at $14.14^{\circ}((110)$ plane, Fig. 2b), $28.47^{\circ}\left((220)\right.$ plane, Fig. 2c) and $31.9^{\circ}((310)$ plane, Fig. 2d) for the pristine $\mathrm{MAPbI}_{3}$ shift to $14.16^{\circ}((110)$ plane $), 28.50^{\circ}((220)$ plane $)$ and $31.93^{\circ}$ ((310) plane) for the $\mathrm{MAPbI}_{3}-2.5 \% \mathrm{PbCl}_{2}$ additive. The shifts is slightly larger than the XRD measurement step $\left(0.015^{\circ}\right)$, suggesting the effect of inclusion of $\mathrm{Cl}$ on the crystal lattice of $\mathrm{MAPbI}_{3}$. Furthermore, the trend illustrating that the more $\mathrm{PbCl}_{2}$ in the $\mathrm{MAPbI}_{3}$ precursor leads to the more shift of the XRD patterns towards the smaller angle of $\mathrm{MAPbI}_{3}$ is observed, confirming that a certain amount of $\mathrm{Cl}$ might be incorporated into the crystal lattice of $\mathrm{MAPbI}_{3}$.

We have attempted to determine the chlorine content in the $\mathrm{MAPbI}_{3}$ films made from the $\mathrm{PbCl}_{2}$ additive based precursor by 
Table 1 Concentration of chloride in the final perovskite films prepared by different contents of $\mathrm{PbCl}_{2}$ in the perovskite precursor

Content of $\mathrm{PbCl}_{2}$ in the perovskite precursor Content of $\mathrm{Cl}^{-}$ions in the perovskite precursor $\left(\%\right.$, molar ratio relative to $\left.\mathrm{MAPbI}_{3}\right)$
Content of $\mathrm{Cl}^{-}$ions in the final perovskite films $\left(\%\right.$, molar ratio relative to $\left.\mathrm{MAPbI}_{3}\right)$
$2.5 \pm 0.2$

$5 \pm 0.2$

$10 \pm 0.2$

$$
\begin{array}{r}
5 \pm 0.4 \\
10 \pm 0.4 \\
20 \pm 0.4
\end{array}
$$

$4.9 \pm 0.2$

$10.1 \pm 0.2$

$20.6 \pm 0.2$

a conventional method such as X-ray photoelectron spectroscopy (XPS) (Fig. S2 $\uparrow$ ). Nevertheless, no characteristic peak of chlorine was detected in the film even in the XPS depth profiling spectrum (Fig. S2 $\dagger$ ). The failure of XPS for detection of $\mathrm{Cl}$ in perovskite films could be due to the strong photon/ion energy, which destroys volatile Cl-based species. Unlike common techniques such as EDS and XPS, ion chromatography (IC) is a highly accurate non-destructive testing method, which guarantees that the measurement does not lose $\mathrm{Cl}$-based species. The chloride content in the final perovskite films prepared from different concentrations of $\mathrm{PbCl}_{2}$ in the perovskite precursor solutions was assessed by IC as demonstrated in Table 1 . It reveals that $\mathrm{Cl}$ remains in perovskite films after a mild annealing $\left(2 \mathrm{~min}, 100{ }^{\circ} \mathrm{C}\right)$ which is consistent with previous reports. ${ }^{5,24}$ The preservation of $\mathrm{Cl}$ in our annealed perovskite films could be due to the high compactness of the as-deposited perovskite film which slows down the rates of diffusion of $\mathrm{Cl}$ to the surface and prevent its loss afterwards. ${ }^{25}$ The exact forms of Cl-based products are beyond the scope of this study; we speculate that the remaining chloride could incorporate into the $\mathrm{MAPbI}_{3}$ lattice, at the GBs, interfaces, or in $\mathrm{MAPbCl}_{3}$ form. The induced $\mathrm{MAPbCl}_{3}$ is not detected in the XRD pattern in low concentration $\mathrm{PbCl}_{2}$-based perovskite films (below 10\%), which is presumably because of the poor crystallinity of the $\mathrm{MAPbCl}_{3}$ like form. ${ }^{5,26}$ Furthermore the unreacted $\mathrm{PbI}_{2}$ passivates GBs which generally worked as recombination centers. ${ }^{2}$

To explore the benefits of the $\mathrm{PbCl}_{2}$-additive in the perovskite precursor on the performance of solar cells, solar cells based on different $\mathrm{PbCl}_{2}$ contents were fabricated and the

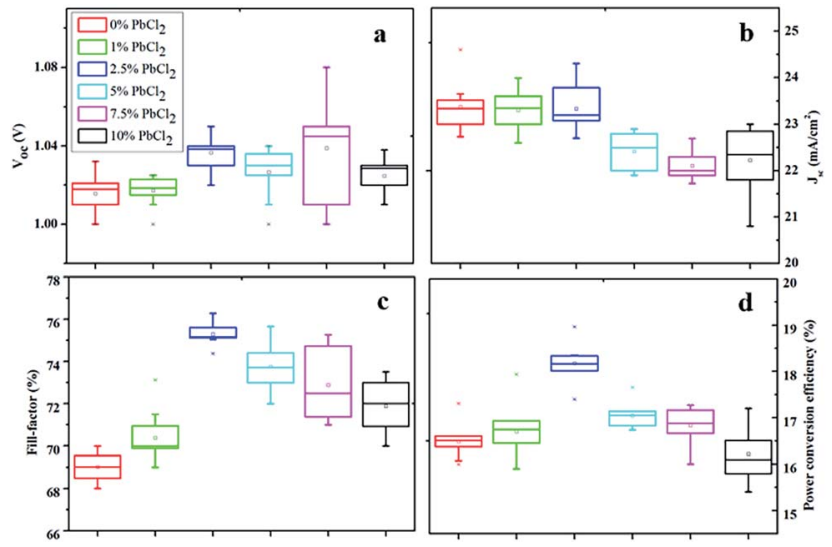

Fig. 3 Statistical parameters of (a) $V_{o c}$, (b) $J_{s c}$, (c) FF, and (d) PCEs measured under reverse scanning $\left(V_{\mathrm{oc}}\right.$, to $\left.J_{\mathrm{sc}}\right)$ for 10 cells using $\mathrm{MAPbl}_{3}$ with varied contents of $\mathrm{PbCl}_{2}$ in the precursor. comparison of $J_{\mathrm{sc}}, V_{\mathrm{oc}}$, FF and PCE is summarized in Fig. 3(a)(d). It is found that the $\mathrm{PbCl}_{2}$-additive does not significantly change the $V_{\mathrm{oc}}$ and $J_{\mathrm{sc}}$ of the solar cells with the content of the $\mathrm{PbCl}_{2}$-additive up to $2.5 \%$. Beyond this, $J_{\mathrm{sc}}$ decreases marginally which is ascribed to reduced light absorption associated with formation of $\mathrm{PbI}_{2}$ impurity and increased voids/pinholes. The most remarkable change is observed with respect to the $\mathrm{FF}$ of the solar cells. When the $\mathrm{PbCl}_{2}$ content is increased from $0 \%$ to $2.5 \%$, the $\mathrm{FF}$ is improved from 0.69 to 0.76 primarily as decreased series resistance $\left(R_{\mathrm{S}}\right)$ and increased shunt resistance $\left(R_{\mathrm{sh}}\right)$ (Table 2). The decrease in $R_{\mathrm{S}}$ is presumably attributed to the reduction of GBs as observed in Fig. 1(a)-(c), while the increase in $R_{\mathrm{sh}}$ corresponds to improved perovskite film quality and more efficient interfacial charge transfer between $\mathrm{MAPbI}_{3}$ and $\mathrm{TiO}_{2}$ film. The increase of $\mathrm{PbCl}_{2}$ concentration to $5 \%$ led to an increased $R_{\mathrm{s}}$ and reduced $R_{\mathrm{sh}}$, which could be due to the occurrence of more pinhole/voids and impurities as discussed above. With further increasing the $\mathrm{PbCl}_{2}$ content to $7.5 \%$, devices exhibited higher $R_{\mathrm{s}}$, yet higher average $R_{\mathrm{sh}}$. However, an extremely large variation was observed, which is possibly related to the non-uniformity of the film due to the distribution of pinhole/voids and a large amount of impurities $\left(\mathrm{PbI}_{2}\right.$ and $\mathrm{MAPbCl}_{3}$ ) in the perovskite film. Thus the devices with the 2.5\% $\mathrm{PbCl}_{2}$ additive result in the maximum FF, which is in line with PCEs obtained. As a result, the best performance devices were obtained with the $2.5 \% \mathrm{PbCl}_{2}$-additive in the precursor solution with an average $J_{\mathrm{sc}}$ of $\sim 23.5 \mathrm{~mA} \mathrm{~cm}{ }^{-2}, V_{\mathrm{oc}}$ of $\sim 1.04 \mathrm{~V}$ and $\mathrm{FF}$ of $\sim 0.75$, leading to an average efficiency of $18.1 \%$ (based on a batch of 10 cells), which is much higher than that of devices without the $\mathrm{PbCl}_{2}$-additive which shows an average PCE of $16.5 \%\left(J_{\text {sc }}\right.$ of $\sim 23.5 \mathrm{~mA} \mathrm{~cm}^{-2}, V_{\text {oc }}$ of $\sim 1.02 \mathrm{~V}$, and FF of $\sim 0.69$ ). The best performance of the $2.5 \% \mathrm{PbCl}_{2}$-additive based cell produced an efficiency of $19 \%$ with details shown in the following section.

Table 2 Average series resistance $\left(R_{\mathrm{s}}\right)$ and shunt resistance $\left(R_{\mathrm{sh}}\right)$ of PSCs measured under reverse scanning with different contents of $\mathrm{PbCl}_{2}$ in the perovskite precursor

\begin{tabular}{llr}
\hline Content of $\mathrm{PbCl}_{2}(\%)$ & $R_{\mathrm{s}}\left(\Omega \mathrm{cm}^{-2}\right)$ & $R_{\mathrm{sh}}\left(\mathrm{k} \Omega \mathrm{cm}^{-2}\right)$ \\
\hline $0 \%$ & $46.9 \pm 5.4$ & $6.8 \pm 1.7$ \\
$1 \%$ & $42.0 \pm 6.3$ & $9.4 \pm 1.9$ \\
$2.5 \%$ & $31.9 \pm 2.9$ & $10.8 \pm 1.8$ \\
$5 \%$ & $34.1 \pm 3.8$ & $8.2 \pm 1.4$ \\
$7.5 \%$ & $38.6 \pm 12.6$ & $14.9 \pm 8.6$ \\
$10 \%$ & $33.8 \pm 6.6$ & $8.1 \pm 1.1$
\end{tabular}



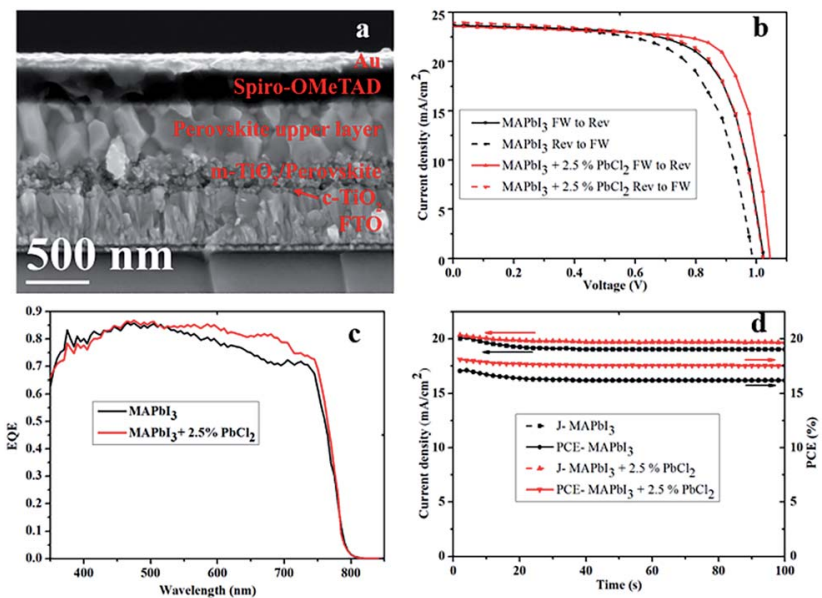

Fig. 4 (a) Cross-sectional SEM image of the completed MAPbl $3+2.5 \%$ $\mathrm{PbCl}_{2}$-additive solar cell; (b) $J-V$ curves of perovskite solar cells using $\mathrm{MAPbl}_{3}$ with and without $2.5 \% \mathrm{PbCl}_{2}$ in the perovskite precursor, under reverse and forward voltage scan; (c) corresponding IPCE spectra; and (d) steady-state photocurrent measured at a bias voltage $(0.85 \mathrm{~V}$ for the $\mathrm{MAPbl}_{3}$ device and $0.89 \mathrm{~V}$ for the $\mathrm{MAPbl}_{3}+2.5 \% \mathrm{PbCl}_{2}$ device) at maximum power point and stabilized power output $10 \mathrm{~s}$ pre-conditioned to 1 sun light illumination.

The detailed cross-sectional SEM structure of a representative solar cell made from the precursor containing the $2.5 \%$ $\mathrm{PbCl}_{2}$-additive in $\mathrm{MAPbI}_{3}$ solution is depicted in Fig. 4a. As depicted, the perovskite layer is homogeneous with large crystals which connect closely and seem to form a monolithic layer from the mesoporous bottom layer to top, suggesting a low density of GBs.

The $J-V$ curves of the $\mathrm{MAPbI}_{3}$ perovskite solar cells with and without $2.5 \%$ of $\mathrm{PbCl}_{2}$ in the perovskite precursor measured under reverse (from $V_{\mathrm{oc}}$ to $J_{\mathrm{sc}}$ ) and forward (from $J_{\mathrm{sc}}$ to $V_{\mathrm{oc}}$ ) scanning are provided in Fig. $4 \mathrm{~b}$. The $\mathrm{MAPbI}_{3}$-based solar cell produces a PCE of $17.1(15.1) \%$, with a $V_{\text {oc }}$ of $1.03(0.98) \mathrm{V}$, a $J_{\text {sc }}$ of 23.7 (23.8) $\mathrm{mA} \mathrm{cm}^{-2}$, and a FF of 70 (65)\% when measured under reverse (forward) scan, respectively, revealing a hysteresis $(H)$ of $11.7 \%\left(H=100 \% \times\left(\mathrm{PCE}_{\mathrm{rev}}-\mathrm{PCE}_{\mathrm{fw}}\right) / \mathrm{PCE}_{\mathrm{rev}}\right)$. In contrast, the $\mathrm{MAPbI}_{3}-2.5 \% \mathrm{PbCl}_{2}$-based solar cell achieved a PCE of 18.9 (17.2)\%, a $V_{\mathrm{oc}}$ of 1.05 (1.03) V, a $J_{\mathrm{sc}}$ of 23.7 (23.9) $\mathrm{mA} \mathrm{cm}^{-2}$, and a FF of 76 (70)\% when measured under reverse (forward) scan, respectively, with only $8.9 \%$ hysteresis.

The external quantum efficiency (EQE) spectra of the $\mathrm{MAPbI}_{3}$-based and $\mathrm{MAPbI}_{3}-2.5 \% \mathrm{PbCl}_{2}$-based device exhibit a high EQE value between $80 \%$ and $86 \%$ across a broad wavelength range from $400 \mathrm{~nm}$ to $750 \mathrm{~nm}$ with the photon response spectral tail extending to around $800 \mathrm{~nm}$ as illustrated in Fig. 4c. The integrated current densities are $20.1 \mathrm{~mA} \mathrm{~cm}^{-2}$ for the device with $\mathrm{MAPbI}_{3}$ and $20.8 \mathrm{~mA} \mathrm{~cm}{ }^{-2}$ for the device with $\mathrm{MAPbI}_{3}-$ $2.5 \% \mathrm{PbCl}_{2}$, which are slightly lower than those measured from $J-V$ curves. This is ascribed to the presence of shallow trap states in the perovskite films. Shallow trap states in perovskite and/or interfaces can be easily filled under illumination during the $J-V$ testing through very short light soaking (10 seconds in our case), which in turn facilitates charge carrier transport. However, the IPCE measurement was performed under very low intensity of monochromatic light without bias illumination. The electron generated in the IPCE measurement first needs to fill the trap states before being collected. ${ }^{27}$ This leads to a minor discrepancy in integrated $J_{\mathrm{sc}}$ from the IPCE spectrum as compared to the $J_{\mathrm{sc}}$ measured by constant steady-state illumination of the solar simulator.

The steady-state performance of the two representative cells $\left(\mathrm{MAPbI}_{3}\right.$ and $\left.\mathrm{MAPbI}_{3}-2.5 \% \mathrm{PbCl}_{2}\right)$ at the maximum power point (MPP) was also measured (Fig. 4d). Both devices were preconditioned by illumination for $10 \mathrm{~s}$ prior to the measurement. The current densities at the MPP drop within a few seconds from $20.1 \mathrm{~mA} \mathrm{~cm}^{-2}$ to $19.1 \mathrm{~mA} \mathrm{~cm}^{-2}$ for the $\mathrm{MAPbI}_{3}$-based solar cell and from $20.4 \mathrm{~mA} \mathrm{~cm}^{-2}$ to $19.7 \mathrm{~mA} \mathrm{~cm}^{-2}$ for the $\mathrm{MAPbI}_{3}-2.5 \%$ $\mathrm{PbCl}_{2}$-based solar cell under a continuous measurement duration of $100 \mathrm{~s}$. The applied voltage bias near the MPP is $0.85 \mathrm{~V}$ for the $\mathrm{MAPbI}_{3}$-based device and $0.89 \mathrm{~V}$ for the $\mathrm{MAPbI}_{3}-2.5 \% \mathrm{PbCl}_{2}$ based device, which has a corresponding stabilized power output of $16.2 \%$ and $17.5 \%$, respectively. This result suggests that addition of $2.5 \% \mathrm{PbCl}_{2}$ into the perovskite precursor also dramatically improves the steady-state efficiency of PSCs.

The steady-state photoluminescence (PL) emission and timeresolved photoluminescence (TRPL) were carried out to elucidate the charge carrier dynamics of $\mathrm{MAPbI}_{3}$ and $\mathrm{MAPbI}_{3}-2.5 \%$ $\mathrm{PbCl}_{2}$ films with and without the presence of charge transport layers $\left(\mathrm{TiO}_{2}\right.$ and Spiro-OMeTAD) (Fig. 5(a)-(d)). Compared to the pristine $\mathrm{MAPbI}_{3}$ perovskite film, the intensity of the PL peak of the $\mathrm{MAPbI}_{3}-2.5 \% \mathrm{PbCl}_{2}$ film increases while the full width half maximum (FWHM) remains constant (Fig. 5a), indicating that more electron-hole pairs in the film lead to stronger radiative recombination. This indicates improved crystallinity of the asdeposited film. ${ }^{28}$ Moreover, the steady-state PL spectrum of the $\mathrm{MAPbI}_{3}-2.5 \% \mathrm{PbCl}_{2}$ film in Fig. 5a depicts a blue-shift by $2 \mathrm{~nm}$ (from $769 \mathrm{~nm}$ to $767 \mathrm{~nm}$ ) which is consistent with the blue-shift observed in UV-vis absorption spectra acquired for the films, further suggesting the incorporation of chloride into the $\mathrm{MAPbI}_{3}$ lattice. On contacting with charge transport layers,
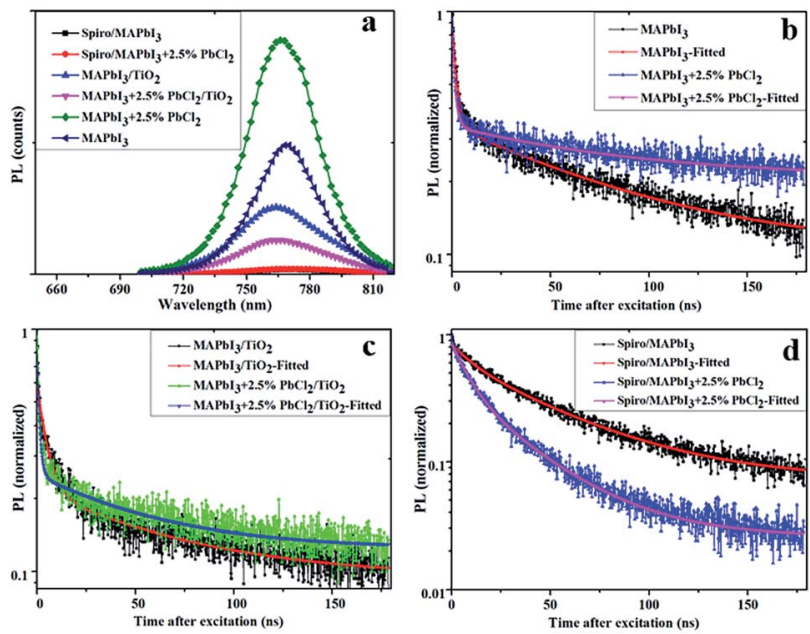

Fig. 5 (a) Steady-state photoluminescence (PL) and normalized timeresolved photoluminescence (TRPL); (b) perovskite; (c) perovskite/ $\mathrm{TiO}_{2} ;$ and (d) Spiro-OMeTAD/perovskite. 
a considerable decrease in PL intensity was observed. Compared to $\mathrm{MAPbI}_{3}$, the drop of PL peaks of $\mathrm{MAPbI}_{3}-2.5 \%$ $\mathrm{PbCl}_{2}$ is more significant when in contact with the $\mathrm{TiO}_{2}$ film, suggesting a more efficient interfacial charge transfer. This is in good agreement with the enhanced performance of $\mathrm{MAPbI}_{3}-$ $2.5 \% \mathrm{PbCl}_{2}$-based PSCs compared to pristine $\mathrm{MAPbI}_{3}$ devices.

The TRPL spectra of samples are fitted using a bi-exponential function of time $(t)\left(F(t)=\sum a_{i} \mathrm{e}^{-t / \tau_{i}}, i=1,2\right)$, which contains a fast decay time component and a slow decay time component. ${ }^{29}$ The fast decay component is associated with recombination behavior at the surface, while the slow decay component corresponds to recombination in the bulk of the perovskite film. ${ }^{30}$ The result indicates that, compared to pristine $\mathrm{MAPbI}_{3}$, addition of $\mathrm{PbCl}_{2}$ into the perovskite precursor results in films with a marginal decrease in the fast decay component (from 2.1 ns to $1.44 \mathrm{~ns}$ ) but longer in the slow component of lifetime (from $80 \mathrm{~ns}$ to $85 \mathrm{~ns}$ ) (Fig. 5b). Therefore the overall average PL lifetime of the perovskite layer is increased from $75 \mathrm{~ns}$ to $80 \mathrm{~ns}$.

Time-resolved photoluminescence measurements of the $\mathrm{MAPbI}_{3}$ show a decrease in the PL lifetime of the perovskite layer from $75 \mathrm{~ns}$ to $56.7 \mathrm{~ns}$ in the presence of $\mathrm{TiO}_{2}(40 \mathrm{~nm}$ compact $\mathrm{TiO}_{2} / 200 \mathrm{~nm}$ mesoporous $\mathrm{TiO}_{2}$ ). When in contact with Spiro-OMeTAD, the lifetime $=45 \mathrm{~ns}$ is obtained. Whereas the $\mathrm{PL}$ lifetime of the $\mathrm{MAPbI}_{3}-2.5 \% \mathrm{PbCl}_{2}$ layer is reduced more significant from $80 \mathrm{~ns}$ to only $49.5 \mathrm{~ns}$ and $26.3 \mathrm{~ns}$, respectively, when in contact with the $\mathrm{TiO}_{2}$ film and with Spiro-OMeTAD layer, indicating a faster and more effective electron and hole transport. The more effective hole transport is crucial for $\mathrm{MAPbI}_{3}$ perovskite due to the unbalanced electron-hole diffusion length ( $\sim 130 \mathrm{~nm}$ for electrons, $\sim 90 \mathrm{~nm}$ for holes) according to a previous report. ${ }^{20}$ These results indicate improved charge collection efficiency of $\mathrm{MAPbI}_{3}-2.5 \% \mathrm{PbCl}_{2}$ based PSCs compared to that of pristine $\mathrm{MAPbI}_{3}$, which is consistent with the improved FF of devices fabricated in this study.

To further explore the possible origin of the superior optoelectronic properties of the $\mathrm{MAPbI}_{3}-2.5 \% \mathrm{PbCl}_{2}$ based solar cell to the pristine $\mathrm{MAPbI}_{3}$ based solar cell, electrochemical impedance spectroscopy (EIS) measurements were conducted and the corresponding Nyquist plots are depicted in Fig. 6. The intercept point at the real part of the Nyquist plots is associated with series resistance of the device $\left(R_{\mathrm{S}}\right)$, which is mainly contributed to the sheet resistance of FTO glass. The small semicircle at high frequency corresponds to the charge transfer process between perovskite and selective contacts while the large semicircle at low frequency demonstrates the recombination of charge carriers in the perovskite layer (according to previous reports). ${ }^{31,32}$ Fitting the EIS of the $\mathrm{MAPbI}_{3}$ and $\mathrm{MAPbI}_{3}-$ $2.5 \% \mathrm{PbCl}_{2}$ solar cells using an equivalent circuit depicted in the inset in Fig. 6 indicates that both devices have comparable interfacial charge transport behavior. Nevertheless, the $\mathrm{MAPbI}_{3}-2.5 \% \mathrm{PbCl}_{2}$ based solar cell has nearly 2.4-times higher resistance for recombination $\left(1.68 \times 10^{5} \Omega\right)$ than the pristine $\mathrm{MAPbI}_{3}$ solar cell $\left(6.93 \times 10^{4} \Omega\right)$, whereas both devices exhibit similar capacitance $\left(0.789 \mu \mathrm{F}\right.$ for $\mathrm{MAPbI}_{3}$ versus $0.769 \mu \mathrm{F}$ for $\mathrm{MAPbI}_{3}-2.5 \% \mathrm{PbCl}_{2}$ ). As a result, the electron lifetime, a product of resistance and capacitance $(\tau=R \times C)$, of the solar

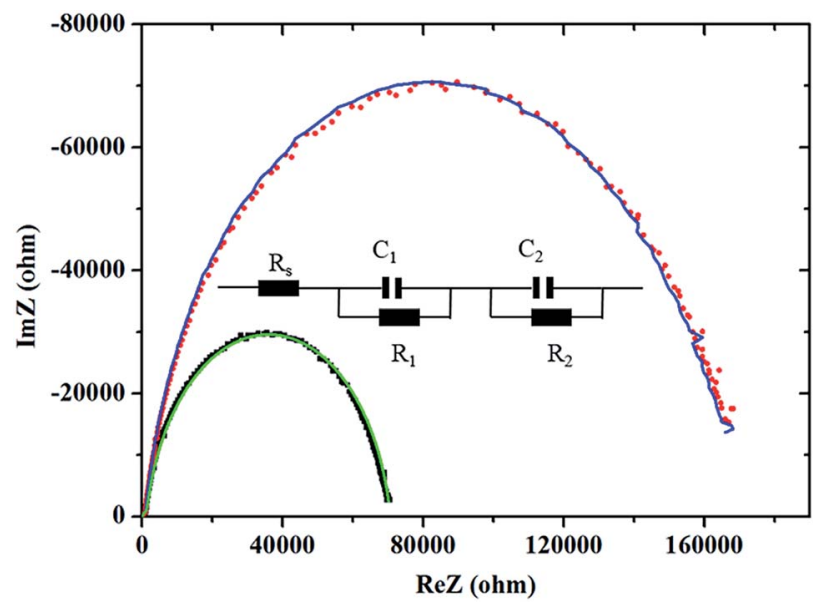

Fig. 6 Nyquist plots of PSCs based on pristine $\mathrm{MAPbl}_{3}$ perovskite (square black) and fitting (green), and $\mathrm{MAPbl}_{3}-2.5 \% \mathrm{PbCl}_{2}$ perovskite (dot red) and fitting (blue) in the dark at $0.5 \mathrm{~V}$ forward bias. The inset depicts the corresponding equivalent circuit.

cell with the $2.5 \% \mathrm{PbCl}_{2}$-additive in the precursor $\left(\tau_{\mathrm{r}}=0.12 \mathrm{~s}\right)$ is over 2-fold higher than the device made from pure $\operatorname{MAPbI}_{3}\left(\tau_{\mathrm{r}}=\right.$ $0.055 \mathrm{~s})$. The increased carrier lifetime is one of the factors that are responsible for the higher performance of the solar cell.

Kelvin probe force microscopy (KPFM) is a powerful technique not only to examine surface topography but also the work function of the surface. The KPFM topography of both pristine $\mathrm{MAPbI}_{3}$ and $\mathrm{MAPbI}_{3}-2.5 \% \mathrm{PbCl}_{2}$ is shown in Fig. 7a and c. It appears that the surface of both perovskite films is uniform over a large area $\left(5 \times 5 \mu \mathrm{m}^{2}\right)$. However, the film made from the $2.5 \%$ $\mathrm{PbCl}_{2}$ based precursor consists of larger grains. The root mean square as an indicator of roughness of the film is $15.75 \mathrm{~nm}$ for the $\mathrm{PbCl}_{2}$-additive film and $14.27 \mathrm{~nm}$ for the pristine $\mathrm{MAPbI}_{3}$

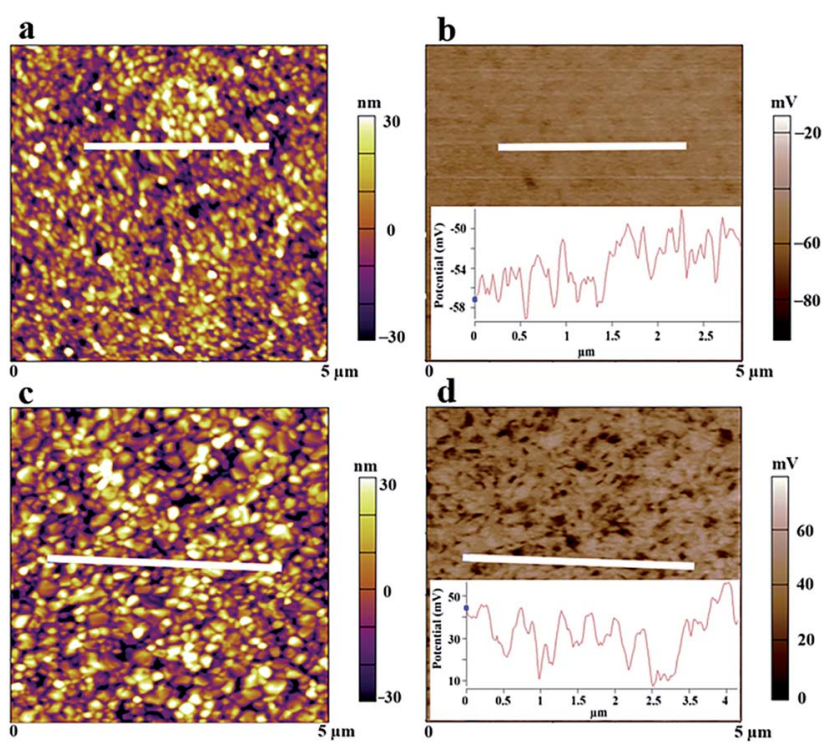

Fig. 7 KPFM topography of the (a) $\mathrm{MAPb}_{3} / \mathrm{mp}-\mathrm{TiO}_{2} /$ compact $\mathrm{TiO}_{2} /$ FTO-glass film and (c) $\mathrm{MAPb}_{3}-2.5 \% \mathrm{PbCl}_{2} / \mathrm{mp}-\mathrm{TiO}_{2} /$ compact $\mathrm{TiO}_{2} /$ FTO-glass film; ( $b$ and d) corresponding contact potential difference (CPD) images. 


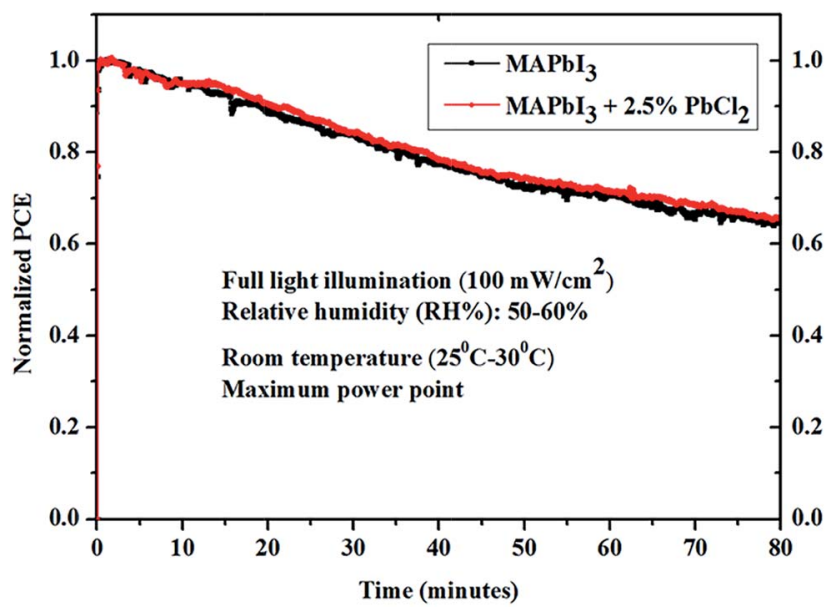

Fig. 8 Relative performance of perovskite solar cells based on $\mathrm{MAPbl}_{3}$ with and without the $2.5 \% \mathrm{PbCl}_{2}$ additive under continuous illumination for 80 minutes in ambient air with relative humidity: 50-60\%.

film. The slightly rougher surface is attributed to its larger grain size. Measurement of the surface potential spectra of $\mathrm{MAPbI}_{3}$ and $\mathrm{MAPbI}_{3}-2.5 \% \mathrm{PbCl}_{2}$ films (Fig. $7 \mathrm{~b}$ and $\mathrm{d}$ ) reveals an increase of mean values of contact potential difference (CPD) by $\sim 90 \mathrm{mV}$ in the $\mathrm{MAPbI}_{3}-2.5 \% \mathrm{PbCl}_{2}$ film compared to the $\mathrm{MAPbI}_{3}$ film. It is known that the conduction band of $\mathrm{MAPbI}_{3}$ perovskite is $\sim 80 \mathrm{meV}$ more negative than that of n-type $\mathrm{TiO}_{2}$, which in principle forms an energy barrier for electron injection from $\mathrm{MAPbI}_{3}$ to $\mathrm{n}-\mathrm{TiO}_{2}$ during the charge transport process. ${ }^{33}$ Therefore, the increase of the electron quasi-Fermi level near the conduction band edge of $\mathrm{MAPbI}_{3}-2.5 \% \mathrm{PbCl}_{2}$ favors improved energy level alignment with adjacent $\mathrm{TiO}_{2}$ for electron transfer at the $\mathrm{MAPbI}_{3}-2.5 \% \mathrm{PbCl}_{2} / \mathrm{n}-\mathrm{TiO}_{2}$ interface. This work provides new insight into the mechanism that governs the impact of $\mathrm{PbCl}_{2}$ on both morphology and electronic properties of the $\mathrm{MAPbI}_{3}$ film for high energy conversion efficiency.

The stability of un-encapsulated perovskite solar cells based on $\mathrm{MAPbI}_{3}$ with and without $2.5 \% \mathrm{PbCl}_{2}$ was tested by aging the device at the maximum power point (MPP) under constant illumination $\left(100 \mathrm{~mW} \mathrm{~cm}^{-2}\right)$ at room temperature in ambient air $(\mathrm{RH} \%=50-60 \%)$. It is found that both devices retained $\sim 65 \%$ power conversion efficiency after 80 minutes stability testing (Fig. 8). The above results suggest that the impact of the $\mathrm{PbCl}_{2}$ additive on the stability of the perovskite solar cells is negligible in this work.

\section{Conclusions}

We have demonstrated the effect of $\mathrm{PbCl}_{2}$ on the morphology, crystallinity and recombination of the $\mathrm{MAPbI}_{3}$ perovskite film that was prepared via a one-step Lewis acid-base adduct method. Although addition of a low content of $\mathrm{PbCl}_{2}$ (less than $2.5 \%$ ) into the $\mathrm{MAPbI}_{3}$ precursor did not pose a significant change in the crystal structure and optical properties, the resulting films show a larger grain size. More importantly, the $\mathrm{PbCl}_{2}$ additive improved the electronic properties and dynamics of charge carriers in the $\mathrm{MAPbI}_{3}$ film. The electronic properties of the perovskite film were modified by the $\mathrm{PbCl}_{2}$ additive with a significant downward shift of the surface work function by 90 $\mathrm{meV}$, which facilitates electron injection from perovskite to $\mathrm{TiO}_{2}$. Analysis of TRPL indicated that the $\mathrm{PbCl}_{2}$-additive in the precursor led to perovskite films with a more balanced charge (electron and hole) collection and longer carrier lifetime. The EIS results of the corresponding PSCs also confirm that devices with the $2.5 \% \mathrm{PbCl}_{2}$ additive have a 2.4 -fold higher resistance for recombination compared to that in the pristine $\mathrm{MAPbI}_{3}$ based solar cell, indicating reduced trap density, resulting in a lower observed current-voltage hysteresis of solar cells. As a result, the performance of PSCs was increased from an average performance of $16.5 \%$ with pristine $\mathrm{MAPbI}_{3}$ to $18.1 \%$ with $\mathrm{MAPbI}_{3}-2.5 \% \mathrm{PbCl}_{2}$. The nearly 9\% enhancement in device performance is mainly due to the improvement of the $\mathrm{FF}$ from 0.69 to 0.76 .

\section{Acknowledgements}

This work was supported by the Australian Research Council Future Fellowship (FT120100674) and Queensland-Chinese Academy of Science (Q-CAS) collaborative research fund. N. D. P. thanks Queensland University of Technology (QUT) postgraduate scholarship and CSIRO top-up scholarship. G. J. W. acknowledges funding support from CSIRO Research Office Julius Career Award and support of the CSIRO top-up scholarship for N. D. P. The data of XRD, SEM, and Ion Chromatography reported in this paper were obtained at the Central Analytical Research facility (CARF), QUT. Access to CARF was supported by the generous funding from Science and Engineering faculty, QUT. Dr Sunny Hu and her team at CARF are acknowledged for the Ion Chromatography measurement. In addition, we acknowledge the measurement of KPMS by Dr Kinnari Shelat at the Queensland node of the Australian national Fabrication Facility (ANFF), a company established under the National Collaborative Research Infrastructure Strategy.

\section{Notes and references}

1 A. Kojima, K. Teshima, Y. Shirai and T. Miyasaka, J. Am. Chem. Soc., 2009, 131, 6050-6051.

2 D. Bi, W. Tress, M. I. Dar, P. Gao, J. Luo, C. Renevier, K. Schenk, A. Abate, F. Giordano, J.-P. Correa Baena, J.-D. Decoppet, S. M. Zakeeruddin, M. K. Nazeeruddin, M. Grätzel and A. Hagfeldt, Sci. Adv., 2016, 2(1), e1501170.

3 M. Saliba, T. Matsui, J.-Y. Seo, K. Domanski, J.-P. CorreaBaena, M. K. Nazeeruddin, S. M. Zakeeruddin, W. Tress, A. Abate, A. Hagfeldt and M. Gratzel, Energy Environ. Sci., 2016, 9, 1989-1997.

4 T.-B. Song, Q. Chen, H. Zhou, S. Luo, Y. Yang, J. You and Y. Yang, Nano Energy, 2015, 12, 494-500.

5 A. Binek, I. Grill, N. Huber, K. Peters, A. G. Hufnagel, M. Handloser, P. Docampo, A. Hartschuh and T. Bein, Chem.-Asian J., 2016, 11, 1199-1204.

6 S. Colella, E. Mosconi, G. Pellegrino, A. Alberti, V. L. P. Guerra, S. Masi, A. Listorti, A. Rizzo, 
G. G. Condorelli, F. De Angelis and G. Gigli, J. Phys. Chem. Lett., 2014, 5, 3532-3538.

7 S. T. Williams, F. Zuo, C.-C. Chueh, C.-Y. Liao, P.-W. Liang and A. K. Y. Jen, ACS Nano, 2014, 8, 10640-10654.

8 H. Yu, F. Wang, F. Xie, W. Li, J. Chen and N. Zhao, Adv. Funct. Mater., 2014, 24, 7102-7108.

9 Y. Tidhar, E. Edri, H. Weissman, D. Zohar, G. Hodes, D. Cahen, B. Rybtchinski and S. Kirmayer, J. Am. Chem. Soc., 2014, 136, 13249-13256.

10 S. D. Stranks, G. E. Eperon, G. Grancini, C. Menelaou, M. J. P. Alcocer, T. Leijtens, L. M. Herz, A. Petrozza and H. J. Snaith, Science, 2013, 342, 341-344.

11 M. M. Lee, J. Teuscher, T. Miyasaka, T. N. Murakami and H. J. Snaith, Science, 2012, 338, 643-647.

12 G. E. Eperon, V. M. Burlakov, P. Docampo, A. Goriely and H. J. Snaith, Adv. Funct. Mater., 2014, 24, 151-157.

13 C. Huang, N. Fu, F. Liu, L. Jiang, X. Hao and H. Huang, Sol. Energy Mater. Sol. Cells, 2016, 145, 231-237.

14 B. Conings, J. Drijkoningen, N. Gauquelin, A. Babayigit, J. D'Haen, L. D'Olieslaeger, A. Ethirajan, J. Verbeeck, J. Manca, E. Mosconi, F. D. Angelis and H.-G. Boyen, Adv. Energy Mater., 2015, 5, 1500477.

15 N. J. Jeon, J. H. Noh, Y. C. Kim, W. S. Yang, S. Ryu and S. I. Seok, Nat. Mater., 2014, 13, 897-903.

16 N. Ahn, D.-Y. Son, I.-H. Jang, S. M. Kang, M. Choi and N.-G. Park, J. Am. Chem. Soc., 2015, 137, 8696-8699.

17 C. Qin, T. Matsushima, T. Fujihara and C. Adachi, Adv. Mater., 2017, 29, 1603808.

18 Z. Xiao, Q. Dong, C. Bi, Y. Shao, Y. Yuan and J. Huang, Adv. Mater., 2014, 26, 6503-6509.

19 P.-W. Liang, C.-Y. Liao, C.-C. Chueh, F. Zuo, S. T. Williams, X.-K. Xin, J. Lin and A. K. Y. Jen, Adv. Mater., 2014, 26, 3748-3754.

20 G. Xing, N. Mathews, S. Sun, S. S. Lim, Y. M. Lam, M. Grätzel, S. Mhaisalkar and T. C. Sum, Science, 2013, 342, 344-347.
21 D.-Y. Son, J.-W. Lee, Y. J. Choi, I.-H. Jang, S. Lee, P. J. Yoo, H. Shin, N. Ahn, M. Choi, D. Kim and N.-G. Park, Nature Energy, 2016, 1, 16081.

22 Y. Li, W. Sun, W. Yan, S. Ye, H. Peng, Z. Liu, Z. Bian and C. Huang, Adv. Funct. Mater., 2015, 25, 4867-4873.

23 H. Xu, Y. Wu, J. Cui, C. Ni, F. Xu, J. Cai, F. Hong, Z. Fang, W. Wang, J. Zhu, L. Wang, R. Xu and F. Xu, Phys. Chem. Chem. Phys., 2016, 18, 18607-18613.

24 J. Chae, Q. Dong, J. Huang and A. Centrone, Nano Lett., 2015, 15, 8114-8121.

25 D. E. Starr, G. Sadoughi, E. Handick, R. G. Wilks, J. H. Alsmeier, L. Kohler, M. Gorgoi, H. J. Snaith and M. Bar, Energy Environ. Sci., 2015, 8, 1609-1615.

26 B. Wang, K. Young Wong, X. Xiao and T. Chen, Sci. Rep., 2015, 5, 10557.

27 T. Yokoyama, D. H. Cao, C. C. Stoumpos, T.-B. Song, Y. Sato, S. Aramaki and M. G. Kanatzidis, J. Phys. Chem. Lett., 2016, 7, 776-782.

28 C. Fei, J. Tian, Y. Wang, X. Liu, L. Lv, Z. Zhao and G. Cao, Nano Energy, 2014, 10, 353-362.

29 D. R. James, Y.-S. Liu, P. De Mayo and W. R. Ware, Chem. Phys. Lett., 1985, 120, 460-465.

30 Q. Dong, Y. Fang, Y. Shao, P. Mulligan, J. Qiu, L. Cao and J. Huang, Science, 2015, 347, 967-970.

31 H.-S. Kim, I. Mora-Sero, V. Gonzalez-Pedro, F. FabregatSantiago, E. J. Juarez-Perez, N.-G. Park and J. Bisquert, Nat. Commun., 2013, 4, 2242.

32 A. Guerrero, G. Garcia-Belmonte, I. Mora-Sero, J. Bisquert, Y. S. Kang, T. J. Jacobsson, J.-P. Correa-Baena and A. Hagfeldt, J. Phys. Chem. C, 2016, 120, 8023-8032.

33 J. P. Correa Baena, L. Steier, W. Tress, M. Saliba, S. Neutzner, T. Matsui, F. Giordano, T. J. Jacobsson, A. R. Srimath Kandada, S. M. Zakeeruddin, A. Petrozza, A. Abate, M. K. Nazeeruddin, M. Gratzel and A. Hagfeldt, Energy Environ. Sci., 2015, 8, 2928-2934. 